\title{
COMPORTAMENTO DA CONCENTRAÇÃO DO METAL MANGANÊS NO SOLO DE ACORDO COM Á SAZONALIDADE
}

\author{
Éder Ramos Paganini ${ }^{1}$
}

Flávio Fernando Manzini ${ }^{2}$

\author{
Lídia Maria de Almeida Plicas ${ }^{3}$
}

\begin{abstract}
RESUMO
A contaminação do solo por metais potencialmente tóxicos é um dos principais problemas ambientais. Por meio da lixiviação e percolação das águas pode ocorrer a contaminação dos mananciais superficiais e subterrâneos, comprometendo sua qualidade. Há, ainda, a possibilidade de esses metais serem disponibilizados para as plantas e, por meio da cadeia alimentar, serem transferidos para o homem. O manganês é um dos elementos mais abundantes na crosta terrestre e se encontra largamente distribuído em solos, sedimentos, rochas, água e materiais biológicos. Esse micronutriente é um elemento essencial para o ser humano. O corpo humano contém pequenas quantidades do mesmo e, em condições normais, as mantém em níveis adequados. Sua carência pode causar perda de peso, fragilidade óssea, dermatite, degeneração do ovário ou testículos e náuseas. Seu excesso pode causar anorexia, alucinações, dificuldade de memorização, insônia, dores musculares e doenças pulmonares e neurológicas. Não há parâmetros orientadores para o teor de manganês, nos solos, do Estado de São Paulo, somente uma orientação. Nesse trabalho foram feitas amostragens de solos da região de São José do Rio Preto após o período de chuvas (mês de março), e em época de franca estiagem (mês de agosto) para se verificar a variação da concentração do metal. Todas as amostras coletadas durante o período de seca apresentaram teores mais elevados do mesmo. A lixiviação teve influência na retirada do metal do solo. As concentrações determinadas são, até 8 vezes, superiores ao valor considerado alto $\left(>5,0 \mathrm{mg} \mathrm{dm}^{-3}\right)$ conforme a orientação do governo paulista.
\end{abstract}

PALAVRAS-CHAVE: Solo. Metais tóxicos. Manganês.

\section{BEHAVIOR OF MANGANESE CONCENTRATION IN SOILS ACCORDING TO THE SEASONALITY}

\footnotetext{
${ }^{1}$ Bacharel em Química Ambiental, Instituto de Biociências, Letras e Ciências Exatas, UNESP-SP. eder_paganini@hotmail.com

${ }^{2}$ Doutor em Geologia Regional, Instituto de Biociências, Letras e Ciências Exatas, UNESP-SP fmanzini@ibilce.unesp.br

${ }^{3}$ Doutora em Físico-Química, Instituto de Biociências, Letras e Ciências Exatas, UNESP-SP plicas@ibilce.unesp.br
} 


\section{Periódica Eletrânica \\ Fórum Ambiental}

da Alta Paulista
Volume 11, Número 08, 2015

Saúde e Saneamento Ambiental

\section{ABSTRACT}

The soil contamination by potentially toxic metals is one of the main environmental problems. Through leaching and percolation of water can occur contamination of surface and ground water sources, affecting their quality. There is also the possibility that these metals are available for plants and through the food chain, are transferred to the man. Manganese is one of the most abundant elements on the earth's crust and is widely distributed in soil, sediments, rock, water and biological materials. This is an essential micronutrient for humans. The human body contains small amounts thereof and, in normal conditions, keeps them at appropriate levels. Its deficiency can cause weight loss, bone weakness, dermatitis, ovarian or testicular degeneration and nausea. Its excess can cause anorexia, hallucinations, difficulty in memorizing, insomnia, muscle pain and pulmonary and neurological diseases. There are no guiding parameters for manganese content in soil for State of São Paulo, only one orientation. In this work were made sampling of soils from São José do Rio Preto region after the rainy season (march), and in times of drought (August) to verify the variation of metal concentration. All samples collected during the dry period presented higher levels of it. Leaching influenced the removal of soil metal. The determined concentrations are up to 8 times higher than the amount considered high $\left(>5.0 \mathrm{mg} \mathrm{dm}^{-3}\right)$ as directed by the state government.

KEY-WORDS: Soil. Toxic metals. Manganese.

\section{COMPORTAMIENTO DE CONCENTRACIÓN DE MANGANESO EN SUELOS DE ACUERDO A LA ESTACIONALIDAD}

\section{RESUMEN}

La contaminación del suelo por metales tóxicos es uno de los principales problemas ambientales. $A$ través de la lixiviación y la percolación del agua puede ocurrir la contaminación de las aguas superficiales y subterráneas, afectando su calidad. También existe la posibilidad de que estos metales están disponibles para las plantas y a través de la cadena alimentaria, se transfieren al hombre. El manganeso es uno de los elementos más abundantes en la corteza terrestre y se encuentra ampliamente distribuido en el suelo, sedimentos, roca, agua y materiales biológicos. Este es un micronutriente esencial para los hombres. El cuerpo humano contiene pequeñas cantidades $y$, en condiciones normales, los mantiene en los niveles apropiados. Su deficiencia puede causar pérdida de peso, debilidad ósea, dermatitis, la degeneración de ovario o testicular y náuseas. Su exceso puede causar anorexia, alucinaciones, dificultad en la memorización, insomnio, dolor muscular y pulmonar y enfermedades neurológicas. No hay parámetros rectores de contenido de manganeso en el suelo por Estado de São Paulo, una sola orientación. En este trabajo se realizaron muestreos de suelos de la región de São José do Rio Preto después de la temporada de lluvias (marzo), y en épocas de sequía (agosto) para verificar la variación de la concentración de metales. Las muestras recogidas durante el período seco presentan niveles más altos de la misma. Lixiviación influyó en la eliminación de metales del suelo. Las concentraciones determinadas son hasta 8 veces mayor que la cantidad considerada elevada $\left(>5,0 \mathrm{mg} \mathrm{dm}^{-3}\right.$ ) por el gobierno estatal.

PALABRAS-CLAVE: Suelo. Los metales tóxicos. El manganeso

\section{INTRODUÇÃO}

Os metais pesados, ou elementos traços ou, ainda, metais potencialmente tóxicos, são metais química e altamente reativos, além de bioacumuláveis, ou seja, os organismos não são capazes de eliminá-los. São aqueles que apresentam alta densidade $\left(>5 \mathrm{~g} / \mathrm{cm}^{3}\right)$, em comparação a outros elementos e número atômico maior 


\section{Periódica Eletranica \\ Fórum Ambiental}

da Alta Paulista
Volume 11, Número 08, 2015

Saúde e Saneamento Ambiental

que 20. Quimicamente, os metais pesados são definidos como um grupo de elementos situados entre o cobre e o chumbo na tabela periódica tendo pesos atômicos entre 63,546 e 200,590. Metais pesados como o mercúrio, chumbo e cádmio não possuem nenhuma função para os organismos e a sua acumulação pode provocar graves enfermidades, sobretudo em mamíferos. Quando lançados como resíduos industriais, na água, no solo ou no ar, esses elementos podem ser absorvidos pelos vegetais e animais das proximidades, provocando graves intoxicações ao longo da cadeia alimentar. Dentre esses metais, o mercúrio $(\mathrm{Hg})$, o chumbo $(\mathrm{Pb})$, o cádmio $(\mathrm{Cd})$ e o arsênio (As) são aqueles que apresentam maiores riscos ambientais. Esse fato se deve ao seu uso intenso, toxicidade elevada e ampla distribuição. Estes metais são resistentes à degradação e podem se acumular nos componentes em que manifestam sua toxicidade. Os locais de fixação final dos metais pesados são os solos e sedimentos (MANZINI et al., 2010; BAIRD, 2002).

Esses metais estão naturalmente presentes nas rochas e nos solos, desde 0 seu processo de formação. Atualmente os solos apresentam maiores concentrações dos mesmos devido à aplicação de corretivos e fertilizantes agrícolas, produtos como lodo de esgoto, compostos de lixo urbano e resíduos de indústria ou mineração, além da utilização de água de irrigação contaminada (FERNANDES et al., 2007). Os graus de mobilidade, atividade e biodisponibilidade desses metais no solo dependem de fatores, como $\mathrm{pH}$, temperatura, potencial redox, CTC, competição com outros metais, ligação com ânions, composição e força iônica da solução do solo. Os seres vivos necessitam de pequenas quantidades de alguns desses metais, incluindo cobalto, cobre, manganês, molibdênio, vanádio, estrôncio, e zinco, para a realização de funções vitais no organismo, porém, níveis excessivos dos mesmos podem ser extremamente tóxicos (OLIVEIRA; COSTA, 2004). O Quadro 1 apresenta alguns desses metais, sua principal fonte e os danos provocados aos organismos. 
Quadro1. Metais pesados, fonte e toxicidade.

\begin{tabular}{|c|c|c|}
\hline Metais pesados & Danos aos organismos & Fonte \\
\hline $\begin{array}{l}\text { Bário } \\
\text { (Ba) }\end{array}$ & $\begin{array}{l}\text { Danos cardiovasculares e ao sistema } \\
\text { nervoso, constrição dos vasos } \\
\text { sanguíneos, aumento da pressão } \\
\text { arterial e morte }\end{array}$ & $\begin{array}{l}\text { Indústrias de cerâmica, } \\
\text { borracha, têxtil }\end{array}$ \\
\hline $\begin{array}{l}\text { Cádmio } \\
\text { (Cd) }\end{array}$ & Carcinogênico e danos renais & $\begin{array}{l}\text { Queima de carvão. Indústrias } \\
\text { de aço, pigmentos, fertilizantes } \\
\text { e pesticidas }\end{array}$ \\
\hline $\begin{array}{l}\text { Cromo } \\
\text { (Cr) }\end{array}$ & Carcinogênico & $\begin{array}{c}\text { Fertilizantes, indústrias de } \\
\text { pigmentos, tintas e fertilizantes }\end{array}$ \\
\hline $\begin{array}{l}\text { Cobre } \\
\text { (Cu) }\end{array}$ & Intoxicação e lesões hepáticas & $\begin{array}{l}\text { Indústrias de tubos, válvulas, } \\
\text { ligas e algicidas }\end{array}$ \\
\hline $\begin{array}{l}\text { Mercúrio } \\
\text { (Hg) }\end{array}$ & $\begin{array}{c}\text { Envenenamento, danos renais e ao } \\
\text { Sistema Nervoso Central e problemas } \\
\text { em fetos }\end{array}$ & $\begin{array}{c}\text { Queima de combustiveis, } \\
\text { incineração de lixo, mineração, } \\
\text { agricultura }\end{array}$ \\
\hline $\begin{array}{l}\text { Manganês } \\
(\mathbf{M n})\end{array}$ & Não é considerado muito tóxico & $\begin{array}{l}\text { Indústrias de vernizes, vidros, } \\
\text { baterias, fertilizantes }\end{array}$ \\
\hline $\begin{array}{l}\text { Níquel } \\
\text { (Ni) }\end{array}$ & Irritação gástrica & $\begin{array}{c}\text { Indústrias de baterias, moedas, } \\
\text { pigmentos, refrigerantes e } \\
\text { mineração }\end{array}$ \\
\hline $\begin{array}{c}\text { Chumbo } \\
\text { (Pb) }\end{array}$ & $\begin{array}{l}\text { Envenenamento, distúrbios no Sistema } \\
\text { nervoso, anemia, doenças } \\
\text { cardiovasculares, danos aos rins, além } \\
\text { de interferir no metabolismo ósseo e na } \\
\text { reprodução }\end{array}$ & $\begin{array}{l}\text { Indústrias de cerâmicas, } \\
\text { plásticos, fertilizantes e } \\
\text { mineração }\end{array}$ \\
\hline $\begin{array}{l}\text { Zinco } \\
(\mathbf{Z n})\end{array}$ & Biocumulativo & $\begin{array}{l}\text { Indústrias de borracha, } \\
\text { protetores solares, vitaminas e } \\
\text { esgotos }\end{array}$ \\
\hline
\end{tabular}

Fonte: PORTELA; SILVA (2010).

O manganês é um dos metais mais abundantes na crosta terrestre. É também um elemento essencial para a vida animal e vegetal. $O$ elemento químico Manganês, representado pelo símbolo $(\mathrm{Mn})$ pertence á classe dos metais de transição, possui número atômico 25 e pertence ao grupo 7 da Tabela Periódica. Apresenta uma coloração cinza clara é quebradiço, e possui alto grau de dureza. Os átomos de manganês, eletricamente neutros, possuem 25 elétrons e 25 prótons. À temperatura ambiente, o elemento puro se apresenta em estado sólido. $O$ isótopo mais abundante, de peso atômico 55, contém 30 neutrons e se cristaliza, habitualmente, na forma cúbica. $O$ manganês não apresenta magnetismo, mas 
forma diversos compostos magnéticos, como os boretos e nitretos. As chamadas ligas de Heusler de manganês, cobre e alumínio se encontram entre as mais magnéticas ligas não ferrosas. Combinado com outros elementos é encontrado em centenas de minerais, embora apenas uma dezena apresente interesse comercial. Destacam-se os seguintes minerais: pirolusita $\left(\mathrm{MnO}_{2}\right)$, psilomelano $\left(\mathrm{MnO}_{2} \cdot \mathrm{H}_{2} \mathrm{O}\right)$, manganita $(\mathrm{MnO}(\mathrm{OH}))$, braunita $\left(3 \mathrm{Mn}_{2} \mathrm{O}_{3} \cdot \mathrm{MnSiO}_{3}\right)$, rodonita $\left(\mathrm{MnSiO}_{3}\right)$, rodocrosita $\left(\mathrm{MnCO}_{3}\right)$, hübnerita $\left(\mathrm{MnWO}_{4}\right)$, entre tantos. O manganês se encontra bem distribuído pela superfície terrestre na forma desses minerais, que são as suas principais fontes (MARTINS; LIMA, 2001 apud MANZINI et al, 2010).

Os compostos de manganês podem ser classificados em orgânicos e inorgânicos. Entre as formas inorgânicas incluem-se as que se encontram nos produtos de combustão no escapamento de automóveis ou caminhões e nos pós que estão presentes na produção de aço ou baterias. As formas orgânicas de manganês são, principalmente, os aditivos para a gasolina e para os praguicidas (MARTINS; LIMA, 2001 e ATSDR apud MANZINI et al., 2010, PRATES, 2011).

Os ciclos do manganês no solo envolvem as formas divalente e trivalente do metal. Há um equilíbrio dinâmico entre todas as formas. A forma divalente é transformada, por meio da oxidação biológica, na forma trivalente que, posteriormente, é reduzida a $\mathrm{Mn}^{2+}$. Em solos muito ácidos, a oxidação bacteriana é considerada baixa, por outro lado, em solos alcalinos, a forma divalente praticamente desaparece. O potencial de oxidação e redução está diretamente relacionado com a atividade dos microorganismos que podem alterar $0 \mathrm{pH}$. A transformação do manganês sofre variação sazonal provavelmente por estar relacionada à ação microbiológica (WHO, 1981 e 1999 apud NASCIMENTO, 2007).

O manganês é um elemento importante para a vida animal e vegetal, mas o consumo ou a exposição elevada pode causar graves problemas. No organismo humano, o metal é absorvido no intestino delgado. A maior parte se acumula no fígado, de onde se dirige para as demais porções do corpo. Exposições prolongadas a compostos de manganês, por inalação ou oralmente, podem provocar efeitos adversos no sistema nervoso, respiratório e outros. O excesso do mesmo acumulado no fígado e no sistema nervoso central provoca sintomas do tipo "Parkinson" (doença degenerativa). Por esses e outros efeitos prejudiciais o manganês é, também, considerado tóxico. Pessoas que consomem água com 
níveis de manganês acima da média apresentam sintomas como rigidez muscular, tremores das mãos e fraqueza. Em animais foi constatado que o excesso de metal no organismo provoca mudanças no cérebro podendo, também, levar à impotência, pois danifica os testículos. Por outro lado a deficiência desse micronutriente causa perda de peso, além de afetar a capacidade reprodutiva, a função pancreática e o metabolismo de carboidratos. O consumo ideal deve estar entre 1 a $5 \mathrm{mg}$ por dia, quantidade que se consegue através dos alimentos como grãos integrais, leguminosas, nozes e chás (SOUZA, 2011).

O objetivo principal deste trabalho foi quantificar o teor do metal manganês pela extração com DTPA-TEA, ácido dietilenotriaminopentaacético + Trietanolamina, disponível em amostras de solo durante período de franca estiagem e promover a comparação dos resultados com aqueles determinados para as mesmas amostras coletadas, anteriormente, após intenso período de chuvas, a fim de se estabelecer o efeito da sazonalidade na disponibilidade do metal no solo.

\section{DESENVOLVIMENTO}

\section{Materiais, equipamentos e metodologias}

\subsection{Materiais e equipamentos}

Os materiais utilizados nesse trabalho foram:

- ferramentas para escavação (pá, martelo, formão)

- 17 amostras de solos

- conjunto de peneiras Bender para granulometria

- almofariz de cerâmica

- vidrarias apropriadas

- pistilos de borracha e de cerâmica

- cadinhos de alumínio

- material de filtragem

- reagentes de grau analítico e água destilada

Os equipamentos utilizados para as análises foram os citados abaixo:

- estufa para esterilização e secagem LOGEN

- medidor de pH Digimed DM22

- mesa agitadora Quimis

- balança analítica OHAUS AS200

- balança semi-analítica Marte A1000

- espectrômetro de absorção atômica modelo AA240FS (EAA)

\subsection{Metodologias}

As amostras de solos foram submetidas a análises granulométricas e análises químicas para determinação de pH. teor de matéria orgânica (M.O.) e de manganês. 


\subsubsection{Metodologia de coleta das amostras de solos}

Foram realizadas duas coletas de amostras de solos (17 amostras) nos mesmos pontos dentro da cidade de São José do Rio Preto e ao longo da Rodovia Washington Luís (SP-310) entre as cidades de Cedral e São José do Rio Preto, em trechos considerados de tráfego elevado. A primeira coleta de amostras foi feita em MARÇO/2012, após o período de chuvas, e a segunda em AGOSTO/2012 durante o período de estiagem. A amostragem se processou conforme os procedimentos propostos por Silva (2009). Dessa forma, limpou-se superficialmente a área a fim de se retirar folhas e restos vegetais, tomando-se o cuidado para não retirar parte do solo. Com o auxílio das ferramentas de escavação foi feita uma cova da qual se retirou o solo. Essas amostras foram colocadas para secar, peneiradas em peneira de malha $2 \mathrm{~mm}$, acondicionadas em sacos plásticos, etiquetados e receberam a sigla de identificação (1-17).

\subsubsection{Metodologia de análise granulométrica}

A caracterização granulométrica das amostras de solos baseou-se no método de pipetagens encontrado em Suguio (1973) no qual foram colocados $50 \mathrm{~g}$ de cada amostra de solo em provetas de $1.000 \mathrm{~mL}$. Foram utilizados $100 \mathrm{~mL}$ de um agente defloculante (no caso, hidróxido de amônia $0,55 \mathrm{~mol} \mathrm{~L}^{-1}$ ) e completado o volume com água. O sistema foi agitado durante $1 \mathrm{~min}$ e foram feitas 2 pipetagens, uma após 58 segundos do término da agitação e outra, após $2 \mathrm{~h}$ e 3 minutos. Na primeira pipetagem foram coletados $20 \mathrm{~mL}$ da solução contendo as partículas de silte+argila e na segunda, outros $20 \mathrm{~mL}$ contendo somente argila. Cada fração coletada foi transferida para um cadinho de alumínio e colocada em estufa para secar. Após a secagem cada uma dessas frações foi pesada e foram feitos os cálculos para correção de volume correspondente aos $1.000 \mathrm{~mL}$ de solução. A quantidade de areia (em peso e em \%) foi estabelecida a partir da equação:

$$
100 \% \text { amostra }=\text { \%areia }-(\% \text { silte }+\% \text { argila })
$$

\subsubsection{Metodologia para determinação do $\mathrm{pH}$ das amostras}

A determinação deste índice foi realizada de acordo com Raij et al. (2001). Dessa forma foram transferidos $10 \mathrm{~g}$ de amostra e $25 \mathrm{~mL}$ de solução de $\mathrm{CaCl}_{2}$ 0,01 
mol $\mathrm{L}^{-1}$ para frascos plásticos que foram tampados com papel filme. Em seguida, esses frascos foram agitados à mão por 1 minuto e deixados em repouso por 15 minutos. Posteriormente foram agitados por 5 minutos em mesa agitadora a 200 rpm e deixados em repouso por 30 minutos. Finalmente, os analitos foram transferidos para tubos Falcon de $50 \mathrm{~mL}$ de plástico e mediu-se o pH diretamente no frasco.

\subsubsection{Metodologia para determinação do teor de matéria orgânica do solo}

O teor de matéria orgânica das amostras de solos foi determinado de acordo com metodologia descrita por Raij et al. (2001) na qual se procede à digestão empregando-se solução de $\mathrm{K}_{2} \mathrm{Cr}_{2} \mathrm{O}_{7} 0,167 \mathrm{~mol} \mathrm{~L}^{-1}$ e $\mathrm{H}_{2} \mathrm{SO}_{4}$ concentrado.

Dessa forma, foi colocado $1,00 \mathrm{~cm}^{3}$ de amostra em erlenmeyer de $250 \mathrm{~mL}$, adicionados $10,0 \mathrm{~mL}$ de solução de $\mathrm{K}_{2} \mathrm{Cr}_{2} \mathrm{O}_{7} \quad 0,167 \mathrm{~mol} \mathrm{L^{-1 }}$ e, rapidamente, adicionados $20,00 \mathrm{~mL}$ de $\mathrm{H}_{2} \mathrm{SO}_{4}$ concentrado. O sistema foi agitado, manualmente, por 1 minuto e deixado em repouso durante 30 minutos.

Foram, então, adicionados 200,0 mL de água destilada e, em seguida, agitouse rapidamente e filtrou-se em papel de filtro de filtragem rápida. O filtrado foi colocado em erlenmeyer de $500 \mathrm{~mL}$. Foram adicionados $10,00 \mathrm{~mL}$ de $\mathrm{H}_{3} \mathrm{PO}_{4}$ concentrado e 8 gotas de indicador difenilamina $1 \% \mathrm{~m} / \mathrm{v}$. Em seguida o sistema foi titulado com solução de $\mathrm{Fe}\left(\mathrm{NH}_{4}\right)_{2}\left(\mathrm{SO}_{4}\right)_{2} \cdot 6 \mathrm{H}_{2} \mathrm{O} \quad 0,4 \mathrm{~mol} . \mathrm{L}^{-1}$ até a viragem de marrom esverdeado $\rightarrow$ verde musgo $\rightarrow$ azul intenso (escuro) $\rightarrow$ verde.

Para o cálculo do teor foi utilizada a relação:

$$
\text { M.O. }\left(g \cdot \mathrm{dm}^{-3}\right)=\left(\mathrm{V}_{\mathrm{br}}-\mathrm{V}_{\mathrm{am}}\right) \times \mathrm{C}_{\mathrm{Fe}}{ }^{2+} \times 0,003 \times 1,33 \times 1,724 \times 1000 / \mathrm{V}_{\text {solo }}
$$

onde M.O. é o teor de matéria orgânica, em $\mathrm{g} \mathrm{dm}^{-3}, \mathbf{V}_{\mathrm{am}}$ é o volume de sulfato ferroso amoniacal gasto na titulação da amostra com solo, $\mathbf{V}_{\mathbf{b r}}$ corresponde ao volume de sulfato ferroso amoniacal gasto na prova em branco e $\mathbf{V}_{\text {solo, ao volume }}$ de solo em $\mathrm{cm}^{3}$. Os fatores multiplicativos são: $\mathbf{0 , 0 0 3}, \mathrm{em} \mathrm{g} \mathrm{mmol}^{-1}$, referente à razão [(0,001 x 12)/4], onde 12 é a massa molar do carbono $\left(\mathrm{g} \mathrm{mol}^{-1}\right), 0,001$ é o fator de transformação em $\mathrm{g} \mathrm{mmol}^{-1}$ e 4 é o número de elétrons na oxidação da M.O. $[\mathrm{C}(0)$ $\rightarrow \mathrm{C}(\mathrm{IV})$, na forma de $\mathrm{CO}_{2}$ ]; 1,33 é o fator de correção para oxidação apenas parcial da matéria orgânica; $\mathbf{1 , 7 2 4}$ é o fator proposto por van Bemmeien, para converter o 


\section{Periádica Eletrânica \\ Fórum Ambiental}

da Alta Paulista
Volume 11, Número 08, 2015

Saúde e Saneamento Ambiental

teor de C orgânico em teor de matéria orgânica e 1000 é o fator de transformação de $\mathrm{cm}^{3}$ para $\mathrm{dm}^{3}$ de solo.

\subsubsection{Determinação de manganês extraído por DTPA-TEA}

A determinação do teor de manganês disponível no solo extraído por DTPATEA, ácido dietilenotriaminopentaacético + Trietanolamina foi realizada a partir da metodologia proposta por Camargo et al. (2009).

Preparo das soluções de trabalho:

a) Solução de DTPA-TEA a pH 7,3: foram dissolvidos 1,96 g de DTPA num béquer com aproximadamente $200 \mathrm{~mL}$ de água destilada. Adicionou-se 13,3 mL de trietanolamina e, em seguida, $1,47 \mathrm{~g}$ de cloreto de cálcio $\left(\mathrm{CaCl}_{2} \cdot 2 \mathrm{H}_{2} \mathrm{O}\right)$. Transferiu-se para um balão volumétrico de $1 \mathrm{~L}$, completou-se o volume com água destilada e agitou-se, manualmente, até a completa dissolução do sal. Quando necessário, o pH foi corrigido com ácido clorídrico concentrado, até o valor 7,3 .

b) Solução-estoque de manganês (1.000 mg/L): foram transferidos 3,0765g de sulfato manganoso $\left(\mathrm{MnSO}_{4} \cdot \mathrm{H}_{2} \mathrm{O}\right)$ para balão volumétrico de $1 \mathrm{~L}$. Em seguida foram adicionados $5 \mathrm{~mL}$ de ácido sulfúrico concentrado e completou-se o volume com água destilada.

c) Solução intermediária de manganês $(50 \mu \mathrm{g} / \mathrm{mL})$ : foram transferidos $10 \mathrm{~mL}$ da solução-estoque de manganês $(1.000 \mathrm{mg} / \mathrm{L})$ para balão volumétrico de 200 $\mathrm{mL}$. Foram acrescentados $5 \mathrm{~mL}$ de solução de ácido clorídrico $6 \mathrm{~mol} \mathrm{~L}^{-1} \mathrm{e}$ completou-se o volume com solução extratora.

Elaboração da curva-padrão:

Inicialmente, foram colocados, em balões volumétricos de $50 \mathrm{~mL}$, os volumes das soluções intermediárias (0,50/2,00/5,00/10,0 e 20,0 mg/L), completando-se com a solução extratora de DTPA-TEA a pH 7,3. Em seguida, foi realizada a medida da absorbância em espectrômetro de absorção atômica, no comprimento de onda $\lambda=279,5 \mathrm{~nm}$.

Após o preparo das soluções-padrão e da construção da curva-padrão, foram colocados $10 \mathrm{~g}$ de amostra de solo em frasco plástico de $50 \mathrm{~mL}$. Foram, então, adicionados, $20 \mathrm{~mL}$ da solução extratora de DTPA-TEA, e este sistema foi agitado 
por 2 h. Procedeu-se à filtragem e à análise por espectrômetro de absorção atômica (EAA).

\section{Resultados e discussões}

\subsection{Caracterização granulométrica das amostras de solo}

Os resultados obtidos do fracionamento granulométrico das amostras de solos se encontram no Quadro 2.

Quadro 2. Resultados das análises granulométricas das amostras de solo.

\begin{tabular}{|c|c|c|c|}
\hline Amostra & $\begin{array}{c}\text { \% Argila } \\
\text { chuva-seca }\end{array}$ & $\begin{array}{c}\text { \% Silte } \\
\text { chuva-seca }\end{array}$ & $\begin{array}{c}\text { \% Areia } \\
\text { chuva-seca }\end{array}$ \\
\hline 1 & $3,23-2,93$ & $13,83-14,21$ & $82,94-82,86$ \\
\hline 2 & $4,28-1,02$ & $18,62-19,17$ & $77,10-79,71$ \\
\hline 3 & $2,19-2,25$ & $13,43-17,55$ & $84,38-80,20$ \\
\hline 4 & $3,22-3,17$ & $16,21-24,86$ & $80,57-71,97$ \\
\hline 5 & $4,37-3,17$ & $12,6-21,67$ & $82,96-75,16$ \\
\hline 6 & $5,60-1,44$ & $11,07-16,54$ & $83,33-82,02$ \\
\hline 7 & $3,55-1,63$ & $12,85-4,61$ & $83,60-93,76$ \\
\hline 8 & $5,16-3,16$ & $11,24-7,45$ & $83,60-89,39$ \\
\hline 9 & $3,56-2,90$ & $26,36-19,19$ & $70,08-77,91$ \\
\hline 10 & $1,98-5,42$ & $9,29-19,47$ & $88,73-75,11$ \\
\hline 11 & $10,06-7,96$ & $12,93-13,64$ & $77,01-78,40$ \\
\hline 12 & $5,64-5,42$ & $14,67-13,15$ & $79,69-81,43$ \\
\hline 13 & $2,73-4,92$ & $4,60-16,43$ & $92,67-78,65$ \\
\hline 14 & $5,41-5,10$ & $12,20-16,35$ & $82,39-78,55$ \\
\hline 15 & $0,77-4,83$ & $5,61-19,49$ & $93,62-75,68$ \\
\hline 16 & $5,67-8,62$ & $13,43-16,56$ & $80,90-74,82$ \\
\hline 17 & $1,57-2,57$ & $6,69-12,25$ & $91,74-85,18$ \\
\hline
\end{tabular}

Fonte: ELABORADO PELOS AUTORES

A exemplo do que se havia determinado quando da coleta pretérita (março/2012), os mesmos solos coletados em agosto/2012 apresentaram-se, também, arenosos porém, a contribuição da fração areia (>0,062 e <2,000 mm), de forma geral, mostrou-se menor do que a determinada anteriormente. Por outro lado, houve um significativo incremento na proporção de partículas do tamanho silte $(<0,062$ e >0,004 mm) e diminuição na proporção de argilas (partículas < 0,004 mm) na maioria das amostras. È provável que essa situação reflita o fato de que as águas das chuvas transportem grande quantidade dos sedimentos mais finos, preservando ou não tendo capacidade de transporte similar para as areias. Em momento de estiagem, os interstícios do material do solo produzidos pela perda anterior seriam preenchidos de forma gradual e constante, no caso, por silte proporcionado, quase que essencialmente, por ventos. 


\subsection{Resultados obtidos para acidez e/ou alcalinidade e teor de matéria orgânica}

\section{das amostras}

Os valores de $\mathrm{pH}$ e de teor de matéria orgânica determinados para as amostras de solos se encontram no Quadro 3.

Quadro 3. Valores de pH e teor de matéria orgânica das amostras de solos.

\begin{tabular}{|c|c|c|c|c|}
\hline amostra & pH chuva & pH seca & M.O. chuva & M.O. seca \\
\hline 1 & 6,20 & 5,86 & 19,05 & 19,11 \\
\hline 2 & 6,85 & 5,93 & 7,26 & 7,43 \\
\hline 3 & 6,25 & 6,62 & 8,23 & 33,45 \\
\hline 4 & 6,34 & 6,60 & 9,58 & 15,03 \\
\hline 5 & 5,88 & 6,23 & 7,88 & 30,38 \\
\hline 6 & 7,33 & 5,31 & 9,27 & 16,97 \\
\hline 7 & 4,91 & 5,52 & 16,10 & 27,96 \\
\hline 8 & 5,26 & 6,32 & 22,40 & 25,05 \\
\hline 9 & 6,86 & 6,90 & 23,44 & 12,26 \\
\hline 10 & 5,43 & 5,58 & 25,03 & 29,29 \\
\hline 11 & 5,12 & 5,23 & 15,78 & 19,61 \\
\hline 12 & 4,90 & 5,81 & 14,65 & 10,92 \\
\hline 13 & 5,44 & 5,95 & 36,04 & 28,05 \\
\hline 14 & 5,41 & 5,14 & 14,94 & 18,61 \\
\hline 15 & 6,01 & 5,85 & 19,04 & 28,05 \\
\hline 16 & 4,55 & 4,32 & 13,18 & 3,47 \\
\hline 17 & 5,67 & 6,12 & 30,47 & 28,30 \\
\hline
\end{tabular}

Fonte: ELABORADO PELOS AUTORES

Conforme a classificação dos solos quanto à sua acidez ou alcalinidade, que constam do Quadro 4, é possível se estabelecer que o $\mathrm{pH}$ dos solos estudados variou dentro das categorias existentes (desde acidez alta até alcalino), impossibilitando quase nenhuma correlação desse parâmetro com os demais obtidos (\%argila e o teor de matéria orgânica). A única observação mais notável seria a discrepância dos resultados observados para a AMOSTRA 6 que, de um pH alcalino, passou a apresentar acidez média quando coletada em época de estiagem. É muito provável que a sensível perda de argilas dessa amostra, quando da segunda coleta seja o fator responsável pela acidificação apresentada.

Quanto aos parâmetros orientadores para o teor de matéria orgânica (M.O.) no solo, disponíveis na Tabela 1, a maioria das amostras apresentou teor de matéria orgânica considerado de nível médio (entre 15 e $50 \mathrm{~g} \mathrm{dm}^{-3}$ ), tanto após as chuvas, quanto durante a estiagem. Observa-se que 12 das 17 amostras continham mais 
M.O. quando foram coletadas na estiagem, o que já era esperado por conta da lixiviação proporcionada pelo período de chuvas.

Quadro 4. Classificação dos resultados para pH em $\mathrm{CaCl}_{2}$.

\begin{tabular}{|c|c|}
\hline Classificação & $\mathbf{p H ~ e m ~} \mathbf{C a C l}_{\mathbf{2}}$ \\
\hline Acidez muito alta & $\leq 4,3$ \\
\hline Acidez alta & 4,4 a 5,0 \\
\hline Acidez média & 5,1 a 5,5 \\
\hline Acidez Baixa & 5,6 a 6,0 \\
\hline Acidez muito baixa & 6,0 a 7,0 \\
\hline Neutro & 7,0 \\
\hline Alcalino & $\geq 7,0$ \\
\hline
\end{tabular}

Fonte: TOMÉ JR. (1997)

Tabela 1. Classificação quanto ao teor de matéria orgânica no solo.

\begin{tabular}{cc}
\hline Classificação & Teor de $\mathbf{M} . \mathbf{0} \cdot\left(\mathbf{g} \cdot \mathbf{d m}^{-3}\right)$ \\
\hline Alto & $>50,0$ \\
médio & 15,0 a 50,0 \\
baixo & $<15,0$
\end{tabular}

Fonte: TOMÉ JR. (1997)

\subsection{Resultados obtidos da extração de manganês por DTPA-TEA}

Os valores das concentrações obtidos para o manganês extraído por DTPATEA, durante o período de chuva intensa e durante o período de estiagem se encontram no Quadro 5.

Vale ressaltar que não há parâmetros orientadores para o teor de manganês nos solos do Estado de São Paulo estabelecidos pela Companhia de Tecnologia de Saneamento Ambiental (CETESB, 2005), mas há uma orientação de interpretação de resultados de análise de solo, do governo do Estado cujos intervalos de classificação se encontram no Quadro 6.

Quadro 5. Teores de manganês das amostras de solos extraído por DTPA-TEA.

\begin{tabular}{|c|c|c|}
\hline Amostra & [Mn após chuvas] $\mathbf{~} \mathbf{g ~ d \mathbf { ~ m } ^ { - 3 }}$ & [Mn estiagem] $\mathbf{~ g ~ d m}^{-3}$ \\
\hline 1 & 17,80 & 20,27 \\
\hline 2 & 4,55 & 8.68 \\
\hline 3 & 11,85 & 20,27 \\
\hline 4 & 11,45 & 11,74 \\
\hline 5 & 5,20 & 15,11 \\
\hline
\end{tabular}




\begin{tabular}{|c|c|c|}
\hline 6 & 3,70 & 12,90 \\
\hline 7 & 12,55 & 21,67 \\
\hline 8 & 11,60 & 14,37 \\
\hline 9 & 13,20 & 22,76 \\
\hline 10 & 27,84 & 39,42 \\
\hline 11 & 9,56 & 19,14 \\
\hline 12 & 8,84 & 18,92 \\
\hline 13 & 19,00 & 28,74 \\
\hline 14 & 7,00 & 21,48 \\
\hline 15 & 5,24 & 21,08 \\
\hline 16 & 3,16 & 9,94 \\
\hline 17 & 9,92 & 10,74 \\
\hline
\end{tabular}

Fonte: ELABORADO PELOS AUTORES

Quadro 6. Valores orientadores para manganês no solo para o Estado de São Paulo.

\begin{tabular}{|c|c|}
\hline Teor & Mn - (DTPA) $\mathbf{~ g ~ d m}^{-3}$ \\
\hline Baixo & $0-1,2$ \\
\hline Médio & $1,3-5,0$ \\
\hline Alto & $>5,0$ \\
\hline
\end{tabular}

Fonte: INTERPRETAÇÃO ANÁLISE DE SOLO GOVERNO SP (PRATES, 2011).

Com relação aos valores obtidos pela extração de manganês com DTPA-TEA, durante o período de estiagem, todas as amostras apresentaram teor superior ao considerado alto para o metal no solo $\left(>5,0 \mathrm{mg} \mathrm{dm}^{-3}\right)$. Na amostragem realizada após as chuvas, a maioria (14) também apresentou esse comportamento. A diferença fica por conta da variação desses teores nesse intervalo de tempo de, aproximadamente, cinco meses.

Pode se notar que as amostras coletadas durante o período de estiagem apresentaram concentrações muito mais elevadas do micronutriente do que o determinado para a amostragem anterior. Essa variação supera $400 \%$ quando se observam os resultados obtidos para a amostra 15. Dessa forma, a lixiviação tem influência importante na retirada do micronutriente manganês do solo.

Os solos utilizados nesse estudo não são cultivados, dessa forma, acredita-se que não receberam resíduos de fertilizantes e/ou pesticidas. Admite-se, então, que o metal seja oriundo do acúmulo de compostos de manganês gerados por emissões de veículos. 


\section{CONCLUSÃO}

Os estudos comparativos realizados para a determinação da concentração do metal manganês, em solos coletados no mês de agosto de 2012, durante o período de seca demonstraram uma significativa variação, para mais, dos teores desse metal do que o determinado, cinco meses antes, em março de 2012, após as chuvas de verão. Dessa forma, demonstra-se que as águas exercem importante função na remoção do metal do solo. Por outro lado, esse metal, assim disponibilizado é, sistematicamente, conduzido aos mananciais superficiais, por essas mesmas águas. É provável, que se esteja acumulando naqueles que estão represados e que constituem fonte de abastecimento para a cidade de São José do Rio Preto. É plausível se supor, também, que uma parte esteja se direcionando ao aquífero freático (superficial) e dele, futuramente, ao subterrâneo através de águas de percolação, uma vez que o solo regional, arenoso, provém da transformação de rochas sedimentares, sotopostas, também arenosas.

Apesar da importância do manganês ao organismo humano, é certo que o seu excesso pode provocar alterações que levam a enfermidades. São poucos os estudos sobre esse tópico. São também raros, os trabalhos que tratam da disseminação do micronutriente na cadeia alimentar, em especial, daqueles que apresentem análises de insumos agrícolas que o possuem em suas formulações e que são utilizados de forma indiscriminada nas práticas agrícolas, o que nos leva a concluir que o manganês deve ser incluído na lista dos metais potencialmente tóxicos, não por sua toxicidade, muito baixa se comparada à de outros metais, mas sim pelo fato de sua abundância, tanto natural, quanto industrializada.

\section{REFERÊNCIAS}

BAIRD, C. Química Ambiental. 2ed. Porto Alegre. Editora Bookman. 622 p. 2002

CAMARGO, O. A. et al. Métodos de Analise Química, Mineralógica e Física de Solos do Instituto Agronômico de Campinas. Campinas, Instituto Agronômico, 2009. 77 p. (Boletim técnico, 106, Edição revista e atualizada). 


\section{Periódica Eletrônica

Orientadores para Solos e Águas Subterrâneas no Estado de São Paulo-2005, em substituição aos Valores Orientadores de 2001, e dá outras providências. Disponível em: $<$ http://www.cetesb.sp.gov.br/Solo/relatorios/tabela valores 2005.pdf. $>$ Acesso em: 24/08/2013

FERNANDES, R. B. A. et al. Avaliação da concentração de metais pesados em áreas olerícolas no Estado de Minas Gerais. Rev. Bras. Eng. Agríc. Ambient. vol.11, n.1, pp. 81-93, 2007. Disponível em:< http://dx.doi.org/10.1590/S1415-43662007000100011. > Acesso em: 17/09/2013.

MANZINI, F. F.; SA, K. B. \& PLICAS, L. M. A. Metais pesados: fonte e ação toxicológica. Fórum Ambiental da Alta Paulista, Periódico Eletrônico, v. VI, p. 800-815, 2010. Disponível em: $<$ http://www.amigosdanatureza.org.br/publicacoes/index.php/forum ambiental/article/view/26/28> Acesso em: 17/09/2013.

NASCIMENTO, S. C. Comportamento de íons e sua associação a resíduos de indústria siderúrgica em manguezal do sistema estuarino de Santos-Cubatão/SP. 2007. 127 f. Tese (Doutorado). Instituto de Geociências, Universidade de São Paulo, São Paulo, 2007.

OLIVEIRA, T. S.; COSTA, L. M. Metais pesados em solos de uma topolitosseqüência do Triângulo Mineiro. Rev. Bras. Ciênc. Solo. vol.28, n.4, pp. 785-796, 2004. Disponível em: $<$ http://dx.doi.org/10.1590/S0100-06832004000400018. . Acesso em: 14/07/2013.

PORTELA E SILVA, C. L. Efeitos dos elementos químicos tóxicos nos seres vivosin EDUCORUMBATAÍ, 2010. Disponível em: <http://educorumbatai.blogspot.com.br/2010/08/efeitosdos-elementos-quimicos-toxicos.html.> Acesso em: 10/09/2013.

PRATES, H. M. Avaliação do teor de manganês solúvel e disponível em amostras de solos do Estado de São Paulo. 2011. 47 f, anexo. Monografia (Trabalho de Conclusão de Curso). Universidade Estadual Paulista, Instituto de Biociências, Letras e Ciências Exatas. 2011.

RAIJ, B.; ANDRADE, J. C. de; CANTARELLA, H.; QUAGGIO, J. A.(ed.). Análise Química para Avaliação da Fertilidade de Solos Tropicais, Instituto Agronômico de Campinas (IAC), Campinas. 2001, 285p.

SILVA, F. C. Manual de análises químicas de solos, plantas e fertilizantes. Embrapa Solos (Rio de Janeiro)/Embrapa Informática Agropecuária (Campinas), 1999, 370p.

SOUZA, L. A. Minerais no organismo: manganês. MUNDOEDUCAÇÃO, 2011. Disponível em: $<$ http://www.mundoeducacao.com.br/quimica/manganes.htm.> Acesso em: 13/07/2013.

SUGUIO, K . Introdução à Sedimentologia, São Paulo: EDUSP. 1973, 317p.

TOMÉ JR., J. B. Manual para interpretação de análise de solo. Guaíba Agropecuária, Rio Grande do Sul. 1997. 247p. 